\title{
The irrelevant speech effect and working memory load
}

\author{
Jens Gisselgård, ${ }^{\mathrm{a}, *}$ Karl Magnus Petersson, ${ }^{\mathrm{a}, \mathrm{b}}$ and Martin Ingvar ${ }^{\mathrm{a}}$ \\ ${ }^{a}$ Cognitive Neurophysiology, MR Research Centre, Department of Clinical Neuroscience, N-8, Karolinska Hospital, Stockholm 17176, Sweden \\ ${ }^{\mathrm{b}}$ Cognitive Neurology and Memory Research Group, F. C. Donders Centre for Cognitive Neuroimaging, University of Nijmegen, The Netherlands
}

Received 16 October 2003; revised 18 February 2004; accepted 18 February 2004

Available online 10 May 2004

Irrelevant speech impairs the immediate serial recall of visually presented material. Previously, we have shown that the irrelevant speech effect (ISE) was associated with a relative decrease of regional blood flow in cortical regions subserving the verbal working memory, in particular the superior temporal cortex. In this extension of the previous study, the working memory load was increased and an increased activity as a response to irrelevant speech was noted in the dorsolateral prefrontal cortex. We suggest that the two studies together provide some basic insights as to the nature of the irrelevant speech effect. Firstly, no area in the brain can be ascribed as the single locus of the irrelevant speech effect. Instead, the functional neuroanatomical substrate to the effect can be characterized in terms of changes in networks of functionally interrelated areas. Secondly, the areas that are sensitive to the irrelevant speech effect are also generically activated by the verbal working memory task itself. Finally, the impact of irrelevant speech and related brain activity depends on working memory load as indicated by the differences between the present and the previous study. From a brain perspective, the irrelevant speech effect may represent a complex phenomenon that is a composite of several underlying mechanisms, which depending on the working memory load, include top-down inhibition as well as recruitment of compensatory support and control processes. We suggest that, in the low-load condition, a selection process by an inhibitory top-down modulation is sufficient, whereas in the high-load condition, at or above working memory span, auxiliary adaptive cognitive resources are recruited as compensation.

(C) 2004 Elsevier Inc. All rights reserved.

Keywords: PET; Working memory; Irrelevant speech; Load; Attention

\section{Introduction}

The irrelevant speech effect (ISE) refers to a reduction in visually presented immediate serial recall caused by irrelevant sound (Colle and Welsh, 1976; Jones and Morris, 1992; Salame and Baddeley, 1982). The primary mechanism of interference is suggested to be a competition between two streams of information containing cues to serial order; one generated from the serial task itself and the other coming from irrelevant auditory items (Jones et al., 1992). The functional anatomical correlate of this effect, based

\footnotetext{
* Corresponding author. Fax: +46-8-51773266.

E-mail address: jens.gisselgard@cns.ki.se (J. Gisselgård).

Available online on ScienceDirect (www.sciencedirect.com.)
}

on the Baddeley-Hitch working memory model (Baddeley, 1992, 2003), is thought to be localized to the verbal component of working memory (Baddeley, 2000; Larsen and Baddeley, 2003) associated with inferior frontal (Awh et al., 1996; Burton, 2001; Smith and Jonides, 1997, 1999), superior temporal (Paulesu et al., 1993; Petersson et al., 2000; Price et al., 1999), and posterior parietal (Awh et al., 1995; Jonides et al., 1998a,b; Paulesu et al., 1993) areas of the brain. In a previous functional imaging study of ISE (Gisselgård et al., 2003), using a relatively low working memory load, the results indicated that the interference from irrelevant speech during immediate serial recall was associated with decreased regional blood flow in the mentioned cortical regions, in particular the superior temporal cortex. These findings were interpreted in terms of a suppression of phonological processing (Ghatan et al., 1998). Given the working memory interpretation of ISE, behavioral studies have shown that the effect occurs in the storage component of the phonological loop (Baddeley and Salame, 1986; Miles et al., 1991) and that interference from the irrelevant speech is unlikely to involve any of the other subsystems of working memory, such as the visuospatial sketchpad or the central executive system (Hanley and Broadbent, 1987; Morris and Jones, 1990; Salame and Baddeley, 1982). However, the ability to suppress distractions is central to the task in irrelevant speech paradigms, and this mechanism is commonly ascribed to the executive component of working memory (Baddeley, 1996; Smith and Jonides, 1999). Tasks that require this ability frequently invoke activity in the prefrontal cortex of the brain (Fuster, 1997), suggesting that this region might play an important role in ISE as well. To address this question, positron emission tomography was used to identify brain regions activated by irrelevant speech at a relatively high working memory load. In the previous study (Gisselgård et al., 2003), the main finding was a bilateral relative deactivation in the superior temporal cortex corresponding to ISE. In this study, we wanted to investigate if this was present also at a higher load.

\section{Materials and methods}

Subjects

Fourteen right-handed (Edinburgh handedness inventory, Oldfield, 1971) healthy male subjects (mean age: 25, 20-37) were included in the study. All subjects were native speakers of Swedish 
and naive as to the literature on irrelevant speech effects and to the specific hypotheses being investigated. The subjects were selected from a pretest of 45 subjects for roughly equivalent span (10-40\% errors in the white noise condition) to have a fairly homogenous group with respect to working memory capacity. The subjects were prescreened and none used any medication, nor had a history of drug abuse (including nicotine), head trauma, neurological or psychiatric illness, or family history of neurological or psychiatric illness. The subjects had 1-5 years of university level education. The study was approved by the local Ethics and Radiation Safety Committees at the Karolinska Hospital. Informed consent was given by all the subjects.

\section{Apparatus and stimuli}

\section{PET scanning technique}

Each subject underwent 12 measurements of $\mathrm{rCBF}$ with a $3 \mathrm{D}$ ECAT EXACT HR PET scanner (Wienhard et al., 1994) and bolus injections of [15-O] water (Fox and Mintun, 1989; Fox et al., 1985) corresponding to about $450 \mathrm{MBq}$ per scan. The PET scanner was used in 3D-sampling mode producing $60 \mathrm{~s}$ tracer uptake images. The different tasks were started at the time of tracer injection and the scanning was automatically initiated when the brain radioactivity exceeded a predetermined level above background. Scatter correction was made and a 2D-transmission scan was taken for attenuation correction.

\section{Stimuli}

Each condition was repeated twice and two sets of lists were used for each condition. Each set consisted of six lists and each list consisted of eight randomly chosen digits from 1 to 9 . The software MacStim 2.2.5 (David Darby, http:/www.brainmapping. org/WhiteAnt/macstim.html) was used for digit presentation at the center of an Apple Power Macintosh G3 computer screen in 80point Geneva font in black on a white background. Each digit was shown $0.5 \mathrm{~s}$ and the interdigit interval was $0.5 \mathrm{~s}$. The time for recall was $6 \mathrm{~s}$.

The irrelevant speech (i.e., the CV pseudowords) and the white noise were auditorily presented with headphones. The single pseudowords and the white noise were presented at a level of 65 $\mathrm{dB}$, and the same level was approximated with the multiple pseudowords (range: 62-68) as measured by a Brüel and Kjær (type 2235) artificial ear. The irrelevant speech was recorded and edited in SoundEdit version 2 with 16-bit resolution and a $22-\mathrm{kHz}$ sampling rate. The digitized speech sounds were normalized to its maximum distortion-free value and passed through a high-pass filter to emphasize high frequencies. Fade-in and fade-out were used to avoid audible clicks at on- and offset of the individual speech sounds. The white noise was generated in SoundEdit version 2 and was created with fade-in and fade-out effects to resemblance the individual sound envelope used in the pseudoword conditions. The serial recall of the subjects was recorded with a Macintosh standard microphone attached to the computer and stored on the hard disk as System 7 Sounds. The irrelevant speech at the single level consisted of repetitions of the identical $\mathrm{CV}$ pseudoword "da" [da:], while the CV pseudowords ne [ne], li [li], to [tu:], vu [vu], py [py], bå [bo:], nö [nœ:] were used at the multiple level in a randomized order. Both the single and the multiple CVs were electronically copied and presented at an approximately even pitch at a frequency of 1 pseudoword/s. The duration of the multiple CV pseudowords was $550 \pm 40$ (mean \pm
$\mathrm{SD}) \mathrm{ms}$ and the duration of the single $\mathrm{CV}$ pseudoword and the white noise was $550 \mathrm{~ms}$. The onsets of the CVs and the digits were not systematically related. Subjects were instructed to ignore any sounds presented in the headphones.

\section{Activation paradigms}

Subjects were scanned in the presence of low background noise and dimmed ambient lighting. Stimuli were presented on a 14-in. computer screen mounted at a viewing distance of approximately $50 \mathrm{~cm}$. The experimental paradigm consisted of a $2 \times 3$ factorial design, including two tasks: immediate serial recall of different digit sequences $(\mathrm{R})$ and immediate serial repetition of the standard digit sequence $(\mathrm{C})$ at three different levels: white noise $(\mathrm{N})$, a single repeated $\mathrm{CV}$ pseudoword $(\mathrm{S})$, and the repetition of multiple $\mathrm{CV}$ pseudowords (M).

\section{The serial recall task}

The subjects engaged in five encoding-recall cycles. After the word "Ready" was displayed on the computer screen, a list was presented. The digits were recalled immediately in serial order after encoding. During recall, a fixation cross was shown on the screen. Subjects were instructed to recall the visually presented digits by auditory serial recall of the digits one by one. The microphone was automatically on- and offset with the presentations of the fixation cross. Subjects were not instructed to memorize the digits using any particular strategy and they were allowed to say "pass" when they were unable to recall the digit for a given position. After $6 \mathrm{~s}$, the word "Ready" appeared again and the next list was serially presented. There were approximately four encoding-recall cycles in each scan.

\section{The serial repetition task}

Serving as a control condition, the serial repetition task consisted of the digits $1-8$ shown in a straightforward order. When all eight digits had been presented, the fixation cross was displayed on the screen the subjects were instructed to enumerate the digits overtly before it disappeared and the word "Ready" appeared again. The stimulus presentation and interval times were the same between the two tasks.

\section{Procedure}

The subjects practiced all aspects of the experimental paradigm (with sham injections) for approximately $20 \mathrm{~min}$ in the PET scanner before the experiment started. To avoid speech artifacts in the PET data, subjects were asked to minimize movements of mouth and tongue during memorizing, but they were allowed to rehearse covertly. The six conditions were presented in a randomized order and repeated in two blocks. The subjects were informed which of the six conditions was next before each scan. After the last scan the subjects were debriefed and asked about their mnemonic strategy.

\section{Data analysis}

The PET images were realigned, spatially normalized, and transformed into a common stereotactic space as defined by the SPM99 template, an approximate Talairach space (Talairach and Tournoux, 1988), 3D isotropic Gaussian filtered (14 mm FWHM), proportionally scaled to account for global confounders, and analyzed with statistical parametric mapping SPM99 version (Well- 
come Department of Cognitive Neurology, http://www.fil.ion.ucl. ac.uk/spm/) running under MATLAB 5.3 (The Mathworks, Inc., Sherbourn MA). Nonspecific, approximately linear, monotone time effects were modeled as confounding covariate using scan order in the general linear model. To test hypotheses about regionally specific condition or covariate effects, estimates were compared using linear contrasts. Our primary regions of interest (ROIs) were brain regions related to a previous irrelevant speech study (Gisselgård et al., 2003) or areas that have previously been shown to be involved in verbal working memory, that is, the superior temporal cortex (Paulesu et al., 1993), the parietal cortex (Awh et al., 1995; Jonides et al., 1998a,b), the ventrolateral (Awh et al., 1996; Burton, 2001; Schumacher et al., 1996; Smith and Jonides, 1999) and dorsolateral (Jonides et al., 1998a,b; Schumacher et al., 1996; Smith and Jonides, 1999) prefrontal cortex as well as the premotor (Awh et al., 1996; Smith and Jonides, 1999) and supplementary motor areas (Schumacher et al., 1996; Smith and Jonides, 1999), the right cerebellum (Paulesu et al., 1993; Smith et al., 1996), and mainly the left hemisphere (Smith et al., 1996). When referring to ROIs according to the prehypothesis, activations were thresholded at the omnibus significance level $P \leq 0.001$. Otherwise, $P$ values were corrected $(\alpha=0.05)$ for multiple nonindependent comparisons based on the theory of smooth T random fields (Worsley et al., 1996). The activated regions were then characterized in terms of spatial extent and peak-height of local maxima. Attempts have been made to take into account the differences between the MNI brain (template used in SPM99) and the brain in the Talairach atlas by utilizing the Talairach Space Utility (Positron Emission Tomography Lab of the Institute of the Human Brain, http://www.ihb.spb.ru/ pet_lab/TSU/ TSUMain.html) in complement with the MNI Space Utility (Positron Emission Tomography Lab of the Institute of the Human Brain, http://www.ihb.spb.ru/ pet_lab/MSU/MSUMain.html), both of which adopt a nonlinear transformations approach, as described at the MRC CBU Imaging web site (http://www.mrc-cbu.cam.ac.uk/ Imaging).

Here we report categorical comparisons and specifically assess the irrelevant speech-related effects as an interaction contrast. The interaction contrast identifies those areas that respond more strongly to the effects of multiple irrelevant pseudowords when working memory load is high. The conventional approach to the data is standard categorical contrasts (e.g., RM - RS), while the interaction approach examines irrelevant speech-related effects using the contrast $[\mathrm{RM}-\mathrm{CM}]-[\mathrm{RS}-\mathrm{CS}]$. Significant effects, $P<0.05$ (small volume correction based on the false discovery rate, Genovese et al., 2002), are reported where explicitly stated.

\section{Results}

\section{Behavioral performance data}

Recall of digits was scored according to serial position giving one point for the right digit in the right place and zero for a wrong digit or "pass". Fig. 1 displays the performance data plotted across serial positions during the PET scans. On average, the probability of recall was $83 \%( \pm 3 \mathrm{SE})$ in the white noise condition and $78 \%$ $( \pm 3 \mathrm{SE})$ in the single-item and multiple-item conditions (Fig. 2A). A Friedman's analysis of variance showed nonsignificance $\left(\chi^{2}=\right.$ 4.04, $P=0.13$ ). However, the suggested effect between the white noise condition and the speech conditions is consistent with our previous study. Rating the degree of difficulty of the auditory

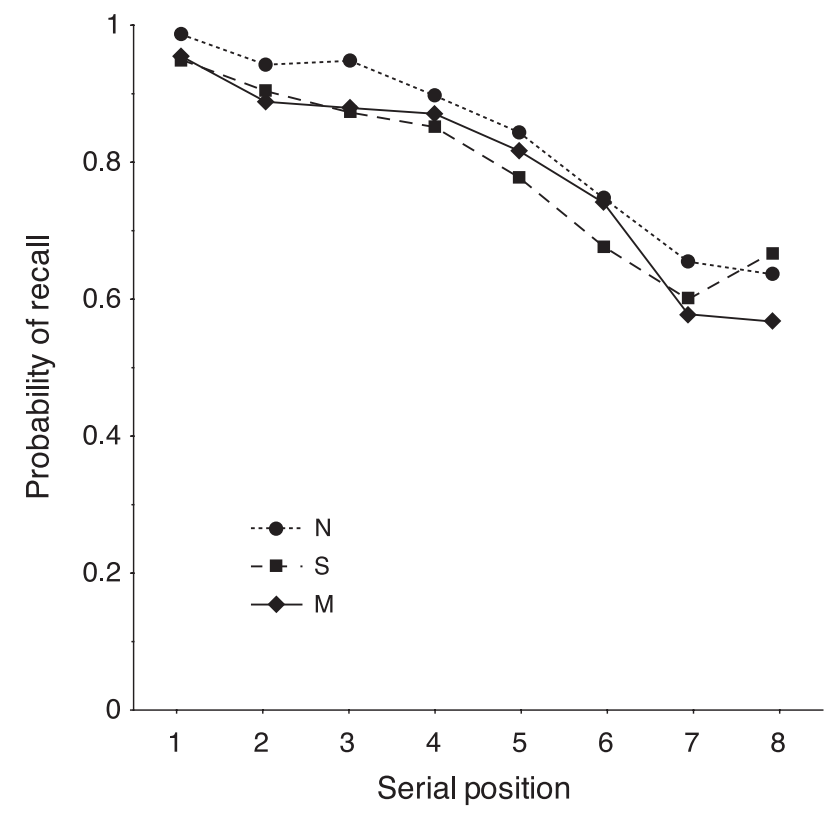

Fig. 1. The irrelevant speech effect displayed as serial position curves for noise $(\mathrm{N})$, single-item (S), and multiple-item (M) auditory background conditions in 10 trials across 14 subjects.

conditions during recall from 0 to 10 , subjects estimated the noise condition to be the easiest (median $=3$ ) and the multiple-item condition to be the hardest (median $=5$ ) while slightly more demanding than the single-item condition (median =4) (Fig. 2B). A Friedman's ANOVA revealed that this difference was significant $\left(\chi^{2}=11.1, P<0.01\right)$. The most common mnemonic strategy was to rehearse the digits in pairs or triplets. Five subjects specifically reported to use a visual strategy for the last two or three digits of the sequence.

\section{PET data}

\section{Working memory effects}

By combining scans from the serial recall tasks and comparing them with the control tasks $([\mathrm{RM}+\mathrm{RS}+\mathrm{RN}]-[\mathrm{CM}+\mathrm{CS}+$ $\mathrm{CN}]$ ), activations related to the main effect of working memory were examined. This analysis revealed significant increases of blood flow (Table 1; Fig. 3A) in the prefrontal region of the brain bilaterally (in the left, BA $9, Z=4.58$ and at a lower threshold BA $46 / 10, Z=3.38$, uncorrected $P<0.001$, and in the right, BA 46/10, $Z=4.58)$. Additional frontal activations were observed in the left inferior frontal cortex (BA 47, 4.71<Z<4.97) as well as in the premotor (left BA 6/9, 5.16<Z<5.89 and right BA $6, Z=5.14$ ) and supplementary motor area (medial part of BA $6, Z=7.41$ ) bilaterally. The anterior cingulate cortex (BA 32, left $Z=6.64$, right $Z=6.58$ ) and the anterior insula (BA $13 / 47$, left $Z=6.45$, right $Z=6.94$ ) were activated bilaterally as well. Parietal increases were detected in the superior parietal lobe, including the left precuneus (BA 7, $Z=5.76$ ) and the right superior parietal cortex (BA 7, $Z=4.95$ ), as well as in the inferior parietal cortex (left BA $40, Z=5.90$ ). Temporal activations were present in the left superior temporal cortex (BA 22, $Z=4.63$ and BA 38, $Z=4.54$ and 4.59). Subcortical increases in blood flow included the cerebellum bilaterally $(5.35<Z<7.55)$, the right lentiform nucleus (globus pallidus, $Z=4.89)$, and the left thalamus $(Z=4.74)$. 
(A)

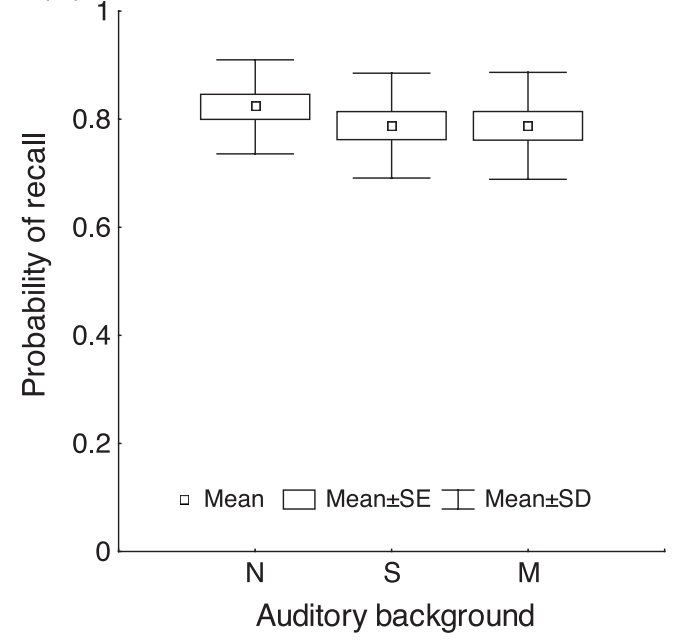

(B)

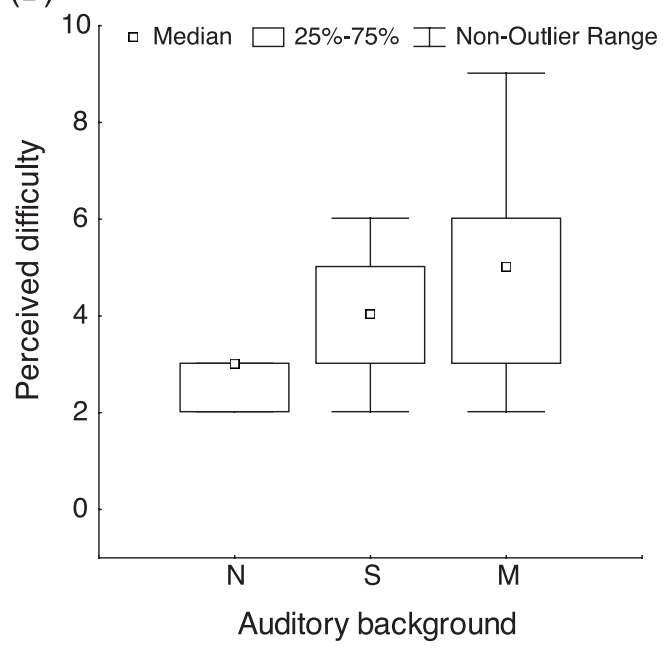

Fig. 2. (A) Probability of serial recall plotted along with standard error and standard deviation bars for noise (N), single-item (S), and multiple-item (M) auditory background conditions. (B) Subjective ratings from the postexperimental interview comparing the perceived difficulty during serial recall in the auditory conditions.

Decreases of activity (Table 2) were present in the medial parts of the prefrontal cortex (BA 10, left $Z=7.11$, right $Z=7.77$, left BA $9, Z=7.47$ ) bilaterally, and the posterior part of the right supplementary area (BA 6, $Z=5.28$ ). Parietal decreases were detected in the right posterior cingulate cortex extending into the precuneus (BA 31, $T=10.07$ ), as well as in the left angular gyrus (BA 39, $T=9.91$ ). Decreases of temporal activity were observed in the right superior (BA 22, $T=8.96$, and BA 39, $Z=7.64$ ), and the left middle (BA 21, $T=9.80$ ) and inferior (BA 20, $Z=7.80$ ) temporal cortices.

\section{The main effect of irrelevant speech}

The main effect of irrelevant speech was examined by comparing irrelevant speech to white noise in conditions of serial recall $(\mathrm{RM}+\mathrm{RS}-2 \mathrm{RN})$. Increases of $\mathrm{rCBF}$ (Table 3) were present in the superior temporal cortex bilaterally (BA 22), in the right bordering to the middle temporal cortex (BA 22/21). Simple main effects of speech minus noise (RM $-\mathrm{RN}$ and $\mathrm{RS}-\mathrm{RN})$ in this region were highly significant as well (corrected $P<0.01$ ). A decrease of blood flow ( $2 \mathrm{RN}-\mathrm{RM}-\mathrm{RS})$ was present in the right supplementary motor area (BA 6, $Z=3.80$ ).

Simple main effects comparing conditions of serial recall during multiple items with those during single items (RM - RS) were localized to the dorsolateral prefrontal cortex bilaterally (BA 9 , left $[x, y, z]=[-34,50,32]$, right $[24,56,34]$, uncorrected $P<$ 0.001 ) as well as the superior-middle temporal cortex bilaterally (left BA 22, [-68, -28, 12], right BA 21/22, [70, -14, -10], uncorrected $P<0.001)$. In the reverse contrast, no significant activity was observed.

\section{The irrelevant speech effect}

ISE is characterized here in terms of the interaction between the level of irrelevant speech (multiple and single items) and working memory (recall and repetition) in the general linear model. Investigating relative increases of activity related to ISE ([RM $-\mathrm{CM}]-$ [RS - CS]), cortical activations were confined to the dorsolateral prefrontal cortices bilaterally (in the left, BA 9/10/46 and 8/9, $Z=$ 3.38 and 3.32, respectively; and the right, BA $9 / 10 / 46, Z=3.22$,
Table 4; Fig. 3B). Subcortical activations were localized to the left cerebellum $(Z=3.88)$. The single area that showed decreased activity in the irrelevant speech interaction comparison was the right cerebellum $(3.64<Z<3.82)$.

\section{Multigroup comparisons}

To compare the results in the present high-load study with those from our previous low-load study (Gisselgård et al., 2003), we performed a multigroup analysis in SPM99 allowing direct comparisons between studies. The experimental design of the previous study was identical to the present one, except for the difference in working memory load and some minor modifications. White noise was used instead of quiet as a baseline auditory condition in the present study. Another difference was that no particular strategy was suggested to the subjects in the present study, while in the previous one, they were instructed to rehearse the digits in triplets.

Similarities between studies were examined through conjunction contrasts (Friston et al., 1999; Price and Friston, 1997) and differences using composite contrasts such as, for example, ([RH $\mathrm{CH}]-[\mathrm{RL}-\mathrm{CL}])$, in this case sensitive to changes in blood flow associated to recall $(\mathrm{R})$ minus control $(\mathrm{C})$ in a high-load $(\mathrm{H})$ state compared to a low-load (L) state.

Main effect of working memory. All regions that were activated in the previous irrelevant speech study were replicated in the present study. In the conjunction analysis, using the contrast showing the main effect of working memory, commonalities of activations between studies included increases of blood flow in the anterior cingulate (BA 24/32), the anterior insula (BA 13/47), the inferior frontal (BA 6/44), and premotor cortex (BA 6) as well as in the posterior parietal cortex (BA 40 and BA 7). Additional activations were observed in the basal ganglia, including the lentiform nucleus and thalamus, as well as the cerebellum.

Main effect of load. The impact of load was assessed by contrasting the main effect of working memory as an interaction contrast between studies (see the example above). One obvious difference between the studies when observing the activation images was the presence of bilateral dorsolateral prefrontal activity 
Table 1

Local maxima of activations observed in the verbal working memory main effect comparison: foci of significant $\mathrm{rCBF}$ increases $(\mathrm{RM}+\mathrm{RS}+\mathrm{RN})-$ $(\mathrm{CM}+\mathrm{CS}+\mathrm{CN})$

\begin{tabular}{|c|c|c|c|c|c|c|c|c|}
\hline \multirow[t]{2}{*}{$\begin{array}{l}\text { Region of } \\
\text { activation }\end{array}$} & \multirow[t]{2}{*}{$\begin{array}{l}\text { Left/ } \\
\text { Right }\end{array}$} & \multirow[t]{2}{*}{$\begin{array}{l}\text { Cluster } \\
\text { size }\end{array}$} & \multirow[t]{2}{*}{$\begin{array}{l}\text { Brodmann's } \\
\text { area }\end{array}$} & \multicolumn{3}{|c|}{$\begin{array}{l}\text { Talairach } \\
\text { coordinates }\end{array}$} & \multirow[t]{2}{*}{$\begin{array}{l}Z \\
\text { score }\end{array}$} & \multirow[t]{2}{*}{$\begin{array}{l}P \\
\text { value }\end{array}$} \\
\hline & & & & $x$ & $\mathrm{y}$ & $\mathrm{z}$ & & \\
\hline \multirow{3}{*}{$\begin{array}{l}\text { Dorsolateral } \\
\text { prefrontal } \\
\text { cortex }\end{array}$} & $\mathrm{L}$ & 2 & 9 & -50 & 26 & 30 & 4.58 & 0.039 \\
\hline & $\mathrm{L}$ & 40 & $46 / 10$ & -32 & 42 & 18 & 3.38 & 0.000 \\
\hline & $\mathrm{R}$ & 5 & $46 / 10$ & 46 & 46 & 20 & 4.58 & 0.039 \\
\hline \multirow{2}{*}{$\begin{array}{l}\text { Inferior } \\
\text { frontal } \\
\text { cortex }\end{array}$} & $\mathrm{L}$ & 7 & 47 & -60 & 16 & -2 & 4.97 & 0.007 \\
\hline & $\mathrm{L}$ & 5 & 47 & -58 & 18 & -6 & 4.71 & 0.023 \\
\hline $\begin{array}{l}\text { Supplementary } \\
\text { motor } \\
\text { cortex }\end{array}$ & $\mathrm{L} / \mathrm{R}$ & 1686 & 6 & 0 & 10 & 48 & 7.41 & 0.000 \\
\hline \multirow{4}{*}{$\begin{array}{l}\text { Premotor } \\
\text { cortex }\end{array}$} & $\mathrm{L}$ & 1393 & $6 / 9$ & -36 & 6 & 26 & 5.16 & 0.003 \\
\hline & $\mathrm{L}$ & 1393 & $6 / 9$ & -52 & 4 & 36 & 5.89 & 0.000 \\
\hline & $\mathrm{L}$ & 1 & 44 & -62 & 14 & 4 & 4.64 & 0.031 \\
\hline & $\mathrm{R}$ & 55 & 6 & 34 & -4 & 56 & 5.14 & 0.003 \\
\hline \multirow{2}{*}{$\begin{array}{l}\text { Anterior } \\
\text { cingulate }\end{array}$} & $\mathrm{L}$ & 1686 & 32 & -4 & 30 & 22 & 6.64 & 0.000 \\
\hline & $\mathrm{R}$ & 1686 & 32 & 12 & 28 & 26 & 6.58 & 0.000 \\
\hline \multirow{2}{*}{$\begin{array}{l}\text { Anterior } \\
\text { insula }\end{array}$} & $\mathrm{R}$ & 686 & $13 / 47$ & 38 & 20 & 2 & 6.94 & 0.000 \\
\hline & $\mathrm{L}$ & 1393 & $13 / 47$ & -26 & 24 & 0 & 6.45 & 0.000 \\
\hline $\begin{array}{l}\text { Superior } \\
\text { parietal } \\
\text { cortex }\end{array}$ & $\mathrm{R}$ & 94 & 7 & 32 & -60 & 52 & 4.95 & 0.008 \\
\hline Precuneus & $\mathrm{L}$ & 723 & 7 & -24 & -66 & 36 & 5.76 & 0.000 \\
\hline $\begin{array}{l}\text { Inferior } \\
\text { parietal } \\
\text { cortex }\end{array}$ & $\mathrm{L}$ & 723 & 40 & -32 & -52 & 42 & 5.90 & 0.000 \\
\hline \multirow{3}{*}{$\begin{array}{l}\text { Superior } \\
\text { temporal } \\
\text { cortex }\end{array}$} & $\mathrm{L}$ & 1 & 22 & -62 & 12 & 0 & 4.63 & 0.032 \\
\hline & $\mathrm{L}$ & 1 & 38 & -60 & 12 & -8 & 4.59 & 0.037 \\
\hline & $\mathrm{L}$ & 1 & 38 & -54 & 16 & -24 & 4.54 & 0.045 \\
\hline \multirow[t]{5}{*}{ Cerebellum } & $\mathrm{L}$ & 734 & & -40 & -60 & -32 & 6.42 & 0.000 \\
\hline & $\mathrm{L}$ & 87 & & -22 & -38 & -42 & 5.35 & 0.001 \\
\hline & $\mathrm{L} / \mathrm{R}$ & 3558 & & 0 & -58 & -30 & 7.14 & 0.000 \\
\hline & $\mathrm{R}$ & 1210 & & 34 & -60 & -30 & 7.55 & 0.000 \\
\hline & $\mathrm{R}$ & 3558 & & 6 & -76 & -24 & 6.66 & 0.000 \\
\hline $\begin{array}{l}\text { Lentiform } \\
\text { nucleus } \\
\text { (globus } \\
\text { pallidus) }\end{array}$ & $\mathrm{R}$ & 38 & & 18 & -4 & 2 & 4.89 & 0.010 \\
\hline Thalamus & $\mathrm{L}$ & 40 & & -6 & -16 & 0 & 4.74 & 0.020 \\
\hline
\end{tabular}

The coordinates of the foci of maximal significant change of rCBF (corrected $P<0.05$, corresponding to $Z=4.45$ ) in the standard stereotactic space of Talairach and Tournoux (1988). $P$ values corrected for multiple comparisons are given in bold type. $P$ values approaching significance $(P<$ 0.001 uncorrected for multiple comparisons, corresponding to $3.05<Z<$ 4.45) are given in plain type.

in the present high-load study. Activations in this region were also observed in the multigroup comparison, specifically in the right dorsolateral prefrontal cortex (right BA 46/10, $[x, y, z]=[48,46$, $10], Z=3.62$, uncorrected $P<0.001)$ as well as in the anterior prefrontal cortex bilaterally (left BA 10/9, $[-30,58,26], Z=3.41$, uncorrected $P<0.001$, right BA 10/9, [20,60,10], $Z=3.64$, uncorrected $P<0.001)$. Activations in prefrontal areas are generally associated with executive processes or working memory load, possibly reflecting the relatively higher working memory load in the present study (see below for a discussion). In addition to these activations, significant activity were located to the right anterior prefrontal cortex (BA 11/10, [24, 58, - 18], $Z=4.91$, corrected $P<$ $0.05)$ and two adjacent clusters in the right medial prefrontal cortex

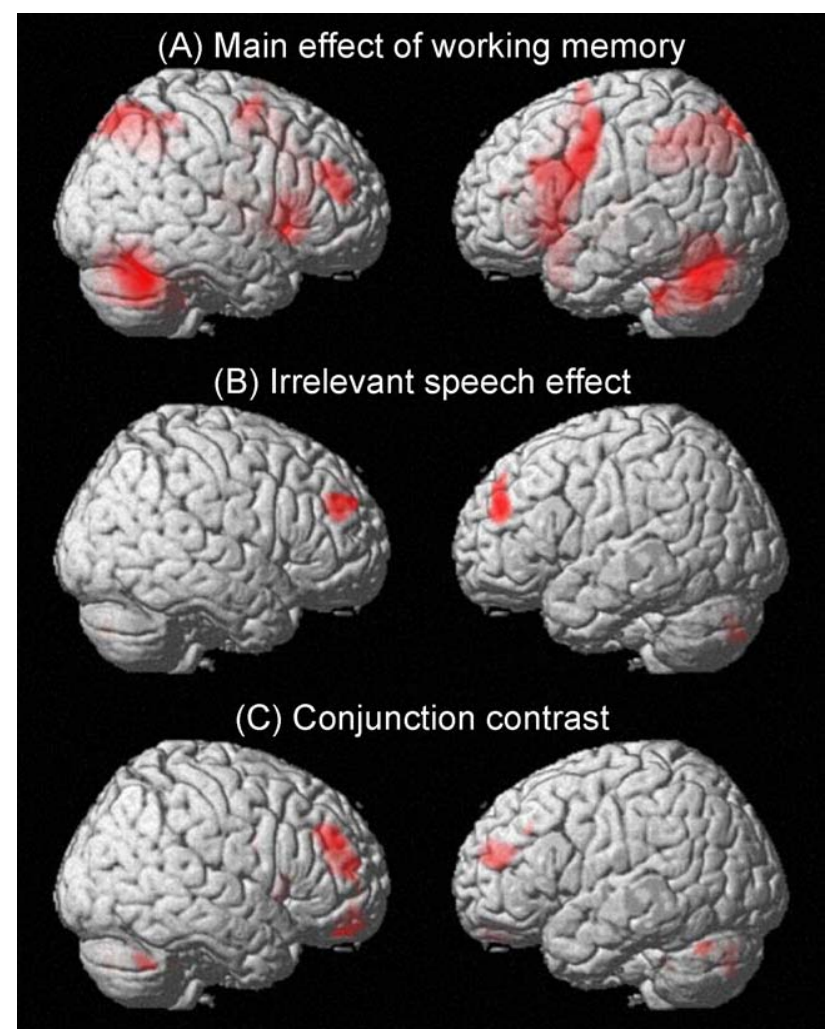

Fig. 3. (A) Increases of blood flow associated with the main effect of working memory ( $P<0.001$ uncorrected for multiple comparisons). (B) Increases of blood flow related to the irrelevant speech effect (for display purposes, pixels are thresholded at the level of $P<0.005$ uncorrected for multiple comparisons). (C) A conjunction contrast of the above, confirming the common activations of the dorsolateral prefrontal cortices $(P<0.001$ uncorrected for multiple comparisons).
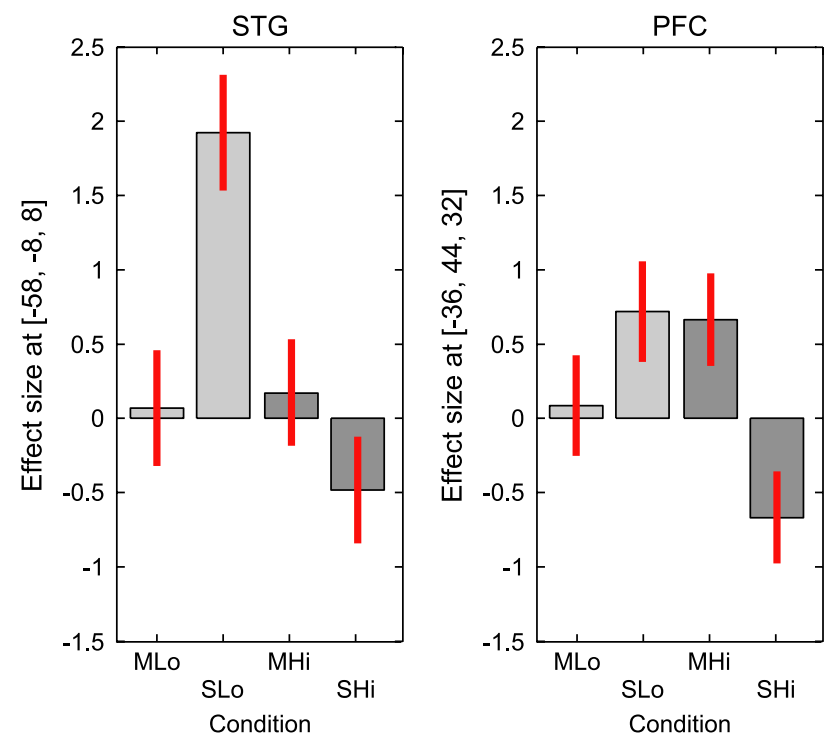

Fig. 4. Effect size (T) in the left superior temporal and prefrontal cortices plotted against conditions of interest in the multistudy comparison. $\mathrm{M}=$ multiple items during recall, $\mathrm{S}=$ single items during recall, Lo $=$ low-load study (light grey), Hi = high-load study (dark grey). 
Table 2

Local maxima of activations observed in the verbal working memory main effect comparison: foci of significant $\mathrm{rCBF}$ decreases $(\mathrm{CM}+\mathrm{CS}+\mathrm{CN})-$ $(\mathrm{RM}+\mathrm{RS}+\mathrm{RN})$

\begin{tabular}{|c|c|c|c|c|c|c|c|c|}
\hline \multirow[t]{2}{*}{$\begin{array}{l}\text { Region of } \\
\text { activation }\end{array}$} & \multirow[t]{2}{*}{$\begin{array}{l}\text { Left/ } \\
\text { Right }\end{array}$} & \multirow[t]{2}{*}{$\begin{array}{l}\text { Cluster } \\
\text { size }\end{array}$} & \multirow[t]{2}{*}{$\begin{array}{l}\text { Brodmann's } \\
\text { area }\end{array}$} & \multicolumn{3}{|c|}{$\begin{array}{l}\text { Talairach } \\
\text { coordinates }\end{array}$} & \multirow[t]{2}{*}{$\begin{array}{l}Z \\
\text { score }\end{array}$} & \multirow[t]{2}{*}{$\begin{array}{l}P \\
\text { value }\end{array}$} \\
\hline & & & & $x$ & $\mathrm{y}$ & $\mathrm{Z}$ & & \\
\hline \multirow{3}{*}{$\begin{array}{l}\text { Medial } \\
\text { prefrontal } \\
\text { cortex }\end{array}$} & $\mathrm{L}$ & 7541 & 10 & -12 & 64 & 6 & 7.11 & 0.000 \\
\hline & $\mathrm{R}$ & 7541 & 10 & 12 & 64 & 14 & 7.77 & 0.000 \\
\hline & $\mathrm{L}$ & 7541 & 9 & -12 & 56 & 28 & 7.47 & 0.000 \\
\hline $\begin{array}{c}\text { Supplementary } \\
\text { motor area }\end{array}$ & $\mathrm{R}$ & 111 & 6 & 6 & -20 & 60 & 5.28 & 0.002 \\
\hline $\begin{array}{l}\text { Posterior } \\
\text { cingulate } \\
\text { cortex/ } \\
\text { Precuneus }\end{array}$ & $\mathrm{R}$ & 2391 & 31 & 4 & -46 & 30 & Inf & 0.000 \\
\hline $\begin{array}{l}\text { Posterior } \\
\text { parietal } \\
\text { cortex }\end{array}$ & $\mathrm{L}$ & 7295 & 39 & -42 & -74 & 32 & Inf & 0.000 \\
\hline \multirow{3}{*}{$\begin{array}{l}\text { Superior } \\
\text { temporal } \\
\text { cortex }\end{array}$} & $\mathrm{R}$ & 9104 & 22 & 60 & -56 & 12 & Inf & 0.000 \\
\hline & $\mathrm{R}$ & 9104 & 22 & 58 & -8 & 2 & Inf & 0.000 \\
\hline & $\mathrm{R}$ & 9104 & 39 & 58 & -62 & 26 & 7.64 & 0.000 \\
\hline $\begin{array}{l}\text { Middle } \\
\text { temporal } \\
\text { cortex }\end{array}$ & $\mathrm{L}$ & 7295 & 21 & -54 & -12 & -10 & Inf & 0.000 \\
\hline $\begin{array}{l}\text { Inferior } \\
\text { temporal } \\
\text { cortex }\end{array}$ & $\mathrm{L}$ & 7295 & 20 & -54 & -20 & -30 & 7.80 & 0.000 \\
\hline
\end{tabular}

(BA 8/9, [6, 32, 44], $Z=4.64$, and [10, 48, 50], $Z=4.63$, corrected $P<0.05)$. In the reverse contrast, sensitive to changes of blood flow related to low load minus high load, significant activations (corrected $P<0.05$ ) were observed in the precentral-premotor cortex (BA 4/6) and the supplementary motor area bilaterally.

Irrelevant speech-related effects. A main finding related to irrelevant sounds from the previous study was a broad decrease of activity in a network of brain areas consistently observed in verbal working memory tasks, including the superior temporal, inferior frontal, and the inferior parietal cortex, predominantly in the left hemisphere. These decreases were not replicated in the present study. However, in the multigroup design analyzing conjunctions over studies, at least some areas related to verbal working memory were commonly activated at low levels of significance (uncorrected $P<0.01)$. These activations included the right superior temporal cortex (BA 42 and 22), as well as the left premotor and supplementary motor cortex (BA 6). Not attaching too much significance to these observations, it might be more relevant to explore the relative

Table 3

Local maxima of activations observed in the irrelevant speech main effect comparison: foci of significant rCBF increases (RM $+\mathrm{RS}-2 \mathrm{RN}$ )

\begin{tabular}{|c|c|c|c|c|c|c|c|c|}
\hline \multirow[t]{2}{*}{$\begin{array}{l}\text { Region of } \\
\text { activation }\end{array}$} & \multirow[t]{2}{*}{$\begin{array}{l}\text { Left/ } \\
\text { Right }\end{array}$} & \multirow[t]{2}{*}{$\begin{array}{l}\text { Cluster } \\
\text { size }\end{array}$} & \multirow[t]{2}{*}{$\begin{array}{l}\text { Brodmann's } \\
\text { area }\end{array}$} & \multicolumn{3}{|c|}{$\begin{array}{l}\text { Talairach } \\
\text { coordinates }\end{array}$} & \multirow[t]{2}{*}{$\begin{array}{l}Z \\
\text { score }\end{array}$} & \multirow[t]{2}{*}{$\begin{array}{l}P \\
\text { value }\end{array}$} \\
\hline & & & & $x$ & $y$ & $z$ & & \\
\hline $\begin{array}{l}\text { Superior } \\
\text { temporal } \\
\text { cortex }\end{array}$ & $\mathrm{L}$ & 444 & 22 & -54 & -16 & 0 & 5.95 & 0.000 \\
\hline $\begin{array}{l}\text { Superior/ } \\
\text { Middle } \\
\text { temporal } \\
\text { cortex }\end{array}$ & $\mathrm{R}$ & 917 & $22 / 21$ & 66 & -14 & -2 & 7.73 & 0.000 \\
\hline
\end{tabular}

Table 4

Local maxima of activations observed in the irrelevant speech interaction comparison: foci of significant $\mathrm{rCBF}$ increases $(\mathrm{RM}-\mathrm{CM})-(\mathrm{RS}-\mathrm{CS})$

\begin{tabular}{|c|c|c|c|c|c|c|c|c|}
\hline \multirow[t]{2}{*}{$\begin{array}{l}\text { Region of } \\
\text { activation }\end{array}$} & \multirow[t]{2}{*}{$\begin{array}{l}\text { Left/ } \\
\text { Right }\end{array}$} & \multirow[t]{2}{*}{$\begin{array}{l}\text { Cluster } \\
\text { size }\end{array}$} & \multirow[t]{2}{*}{$\begin{array}{l}\text { Brodmann's } \\
\text { area }\end{array}$} & \multicolumn{3}{|c|}{$\begin{array}{l}\text { Talairach } \\
\text { coordinates }\end{array}$} & \multirow[t]{2}{*}{$\begin{array}{l}\mathrm{Z} \\
\text { score }\end{array}$} & \multirow[t]{2}{*}{$\begin{array}{l}P \\
\text { value }\end{array}$} \\
\hline & & & & $x$ & $\mathrm{y}$ & $\mathrm{Z}$ & & \\
\hline Dorsolateral & $\mathrm{L}$ & 50 & $9 / 10 / 46$ & -32 & 46 & 28 & 3.38 & 0.000 \\
\hline prefrontal & $\mathrm{L}$ & 10 & $8 / 9$ & -26 & 48 & 40 & 3.32 & 0.000 \\
\hline cortex & $\mathrm{R}$ & 18 & $9 / 10 / 46$ & 36 & 44 & 26 & 3.22 & 0.001 \\
\hline Cerebellum & $\mathrm{L}$ & 86 & & -12 & -78 & -40 & 3.88 & 0.000 \\
\hline
\end{tabular}

differences in rCBF levels induced by irrelevant speech in a direct comparison between the two studies, again characterized as interaction contrasts. The contrast showing relatively greater activity related to decreases induced by irrelevant speech in the low-load compared to high-load study revealed a weak activation in the left superior temporal cortex (BA 22, $[-60,-6,6],, Z=3.28$, uncorrected $P<0.001)$. This is, perhaps not surprisingly, the same area that was most significantly decreased in the low-load study. In the reverse contrast, the relative increase of prefrontal activation associated to irrelevant speech observed in the high-load study, did not, however, withstand a direct comparison even at low levels of significance.

\section{Discussion}

Concurrent with a limited behavioral effect of irrelevant speech, the activation images related to ISE revealed significant increases in regional blood flow in the dorsolateral prefrontal cortex bilaterally. This finding is consistent with the general suggestion that the ability to suppress distractions, which is central to the ISE task, is subserved by the central executive, a subsystem of working memory that has previously been shown to be associated with prefrontal cortex.

\section{Behavioral effect size}

The effect size of irrelevant speech is typically in the order of 30\% (Baddeley and Salame, 1986; Colle, 1980; Colle and Welsh, 1976; Hanley and Broadbent, 1987; Jones and Macken, 1993; Miles et al., 1991; Salame and Baddeley, 1982, 1987, 1989), while in the present experiment it was about $5 \%$. Several factors may explain the relatively small effect size, such as the use of an isolated syllable at a relatively slow presentation rate (i.e., a low "word-dose" (Bridges and Jones, 1996)), the lack of a delay period between presentation and recall, or the low degree of pitch variability in the irrelevant speech input (Jones and Macken, 1993). A performance rate of $78 \%$ in the irrelevant speech conditions is an acceptable accuracy level indicating continued engagement of the participants in the task. However, this also suggests that the subjects' working memory capacity was close to ceiling or perhaps even exceeded in some cases (Braver et al., 1997).

\section{Working memory}

Previous functional imaging studies lend considerable support to a working memory related network in the brain that is typically associated with the prefrontal cortex, anterior cingulate, and 
parietal regions (Cabeza and Nyberg, 2000). Consistent with these findings, the main effect of working memory in the present study included significant prefrontal (BA 9, 46/10, 47), cingulate (BA 32 ), and posterior parietal activations (BA 7, 40), as well as several additional activations in regions also previously associated with the verbal component of working memory. These included the left superior temporal cortex (Ghatan et al., 1998; Paulesu et al., 1993), the premotor (BA 6) (Awh et al., 1996; Smith and Jonides, 1999) and supplementary motor areas (Schumacher et al., 1996; Smith and Jonides, 1999), as well as the cerebellum (Paulesu et al., 1993; Smith et al., 1996).

\section{Irrelevant speech effects}

The relative decreases of activity related to ISE that were observed in the previous low-load study were not replicated in the present study. This may be due to limited statistical power or lack of detection sensitivity (cf. below). However, in the reversed contrast, sensitive to the relative increases associated with ISE, bilateral dorsolateral prefrontal activations were observed. Interpretations of prefrontal activations in association to working memory are generally a fractionation either by modality (Goldman-Rakic, 1995) or cognitive process (Petrides, 1995). An important distinction among the advocates of processing specificity is that between passive maintenance of information and active manipulation of this information (Fletcher and Henson, 2001). Consistent with this distinction, several functional imaging studies suggest that the ventrolateral prefrontal cortex is associated with maintenance (Awh et al., 1996; Jonides et al., 1993; Paulesu et al., 1993; Smith et al., 1996), whereas the dorsolateral prefrontal cortex is associated with manipulation (Braver et al., 1997; D'Esposito et al., 1999a,b; Postle et al., 1999). Mapping this framework onto the model of Baddeley and Hitch, it is suggested that the ventrolateral prefrontal cortex is involved in operations related to the slave systems such as the phonological loop, while the dorsolateral prefrontal cortex is primarily involved in or recruited by tasks requiring additional executive processing and control. In the present study, the main effect of working memory encompassed both the ventrolateral (BA 44 and 47) and the dorsolateral (BA 9 and 46) prefrontal regions, indicating that processes related to both maintenance and manipulation were involved. In contrast, activations specifically related to the ISE were confined to the dorsolateral prefrontal cortex, suggesting a role previously not recognized for the central executive in ISE literature. In general terms, such a role might be to control and facilitate the processing of task-relevant information (Chawla et al., 1999; Shulman et al., 1997), or inhibit processing of taskirrelevant information. In the context of irrelevant speech, it would be beneficial to increase the internally generated signal representing the items to be remembered while inhibiting the processing related to the irrelevant auditory input. Behavioral inhibition (Dempster, 1991) has frequently been associated with activity in the ventrolateral prefrontal cortex (D'Esposito et al., 1999a,b; Jonides et al., 1998a,b) as opposed to the dorsolateral prefrontal cortex. However, it should be noted that dorsolateral prefrontal (Casey et al., 1997) and frontopolar activations (Sylvester et al., 2003) have been reported in relation to behavioral inhibition, although these and most other studies of behavioral inhibition refer to inhibition of motor or verbal behavior rather than to the resolution of interference from irrelevant input, as would be the primary function of interest in the present study. A recent study
(Bunge et al., 2001) directly examined the relationship between working memory and behavioral inhibition. The results suggested that these were highly interdependent, sharing a common neural circuitry, and that the ability to suppress irrelevant information effectively or to enhance representation of task-relevant information correlated with activation in a right dorsolateral area (BA 9, $[44,16,36]$ ) (for a review, see Miller and Cohen, 2001). To relate this finding to our data, a conjunction contrast incorporating the main effect of working memory and increases due to irrelevant speech (Fig. 3C) revealed significant activations of the dorsolateral prefrontal cortices bilaterally (Right 9/46, [38, 42, 28], $Z=4.71$, corrected $P<0.05$ and Left 9/10/46, [-34, 44, 22], $Z=4.65$, corrected $P<0.05)$. These findings suggest that the capacity to sustain task performance in the context of interfering irrelevant distractors is mediated by a subset of the areas supporting working memory, providing some support for a common neurophysiological nature of these processes.

\section{General comparison between the low-load and high-load study}

In addition to several commonalities, there were also important differences between the previous low-load and the present highload experiment (Fig. 4).

There are several explanations for the apparent disparity between the two studies. In addition to potential explanations related to a lack of statistical power, statistical specificity, or differences in performance variability (study $2>$ study 1 ), there may, in the second high-load experiment, be a relative lack of dynamic $\mathrm{rCBF}$ range compared to the low-load experiment. More generally, with respect to certain brain regions, the second study may be affected by a neuronal or neurophysiological ceiling effect. It is thus possible that the higher load in the present experiment engaged a (close to) maximum level of attentional modulation already in the less demanding single irrelevant item condition. The greater performance demands in the present study are also indicated by the lower average scores compared to the low-load study ( $83 \%$ vs. $94 \%$ ). Consequently, it is not possible to exclude that an inhibitory effect of phonological processing was masked by ceiling effects. Indirect support for this suggestion comes from the fact that the main and simple main effects of multiple items compared to single items $([\mathrm{RM}+\mathrm{CM}]-[\mathrm{RS}+\mathrm{CS}],[\mathrm{RM}-\mathrm{RS}]$, and $[\mathrm{CM}-\mathrm{CS}])$ were associated with an increased level of activity in the superior temporal cortices bilaterally. This indicates that the multiple items were potentially more disturbing or distracting than the single items in the baseline condition as well as in the condition of interest. Beyond these potential explanations there are also several more interesting possibilities. For example, Salame and Baddeley (1986) investigated the interaction between the irrelevant speech effects and phonological similarity effects across a range of list lengths. For sequences of five, six, and seven items, marked effects of similarity were observed under both control and irrelevant speech conditions, while at a list length of eight, the similarity effect disappeared. This pattern was interpreted in terms of a tendency of the subjects to shift from pure phonological processing towards engaging semantic processes as well when performance dropped below some critical level. This is also supported by additional behavioral results (Baddeley, 1966a,b; Hanley and Bakopoulou, 2003; Larsen and Baddeley, 2003; Salame and Baddeley, 1986). Furthermore, there are several studies in the WM imaging literature manipulating load in the absence of external distractors, which have reported quite different patterns 
of DLPFC activity as a function of load, including linear (Braver et al., 1997), stepwise (Jonides et al., 1997), or inverted U (Callicott et al., 1999). In particular, the stepwise and the inverted U-shaped response has been taken as evidence for a qualitatively different type of WM processing. In our previous irrelevant speech study (Gisselgård et al., 2003), we observed a suppressive effect of irrelevant speech. The inhibition of several brain regions related to verbal working memory indicated that the subjects were using a phonological code to recall the digits and that the irrelevant speech was interfering with this coding. In the present experiment, we increased the working memory load from six to eight digits and suggest that the subjects, adapting to the high-load context, start to engage executive support and control processes supported by the prefrontal cortex. Thus, to maintain task performance, this might indicate a compensatory mechanism associated with a relative transition towards an alternative mnemonic strategy. The present finding that ISE was associated with increases of activity in prefrontal regions is in line with the general suggestion that when working memory resources for phonological coding are exceeded, whether it is a consequence of load or adding irrelevant speech, adaptive executive control is called for. Preliminary results from a recent network analysis (Petersson et al., in manuscript) of the lowload imaging data suggest that different brain regions of interest interact differently in reaction to the level of irrelevant speech, including the interaction between the verbal working memory and the medial temporal lobe memory systems in the multiple-item condition compared to the single-item condition.

Finally, another issue related to the activity or absence of such in the superior temporal cortex pertains to the potential lexicalsemantic nature of the irrelevant items. The bigram used in the single-item condition ("da" [da:]), although a pseudoword in written form in Swedish, may under some circumstances in its spoken form carry a semantic value (the word "day" in Swedish). Lexical processing would presumably induce activity in the similar temporal regions of the brain as phonological processing, constituting a potential confound for a pure phonological interpretation. However, the main effect of multiple items compared to single items revealed activations in the superior temporal cortex bilaterally in both studies, supporting an interpretation based on phonological variability comprising the main difference between the auditory conditions. Consistent with this hypothesis, semantic effects of the auditory material have not been found in ISE experiments (Buchner et al., 1996; Jones et al., 1990; LeCompte and Shaibe, 1997; Salame and Baddeley, 1982, 1987; but see LeCompte et al., 1997).

\section{Conclusions}

We suggest that the two irrelevant speech studies together provide insights into the nature of ISE. Firstly, it appears that no single area in the brain can be ascribed as the single locus of ISE. Instead, the effect can be characterized in terms of a network of changes in functionally interrelated areas. Secondly, the areas that show irrelevant speech-related changes of activity are the same brain regions that are generically activated by the verbal working memory task itself. Finally, the impact of irrelevant speech and related brain activity depends on working memory load, as indicated by the differences between the present and the previous study. These findings indicate that working memory load (i.e., list length) is an important parameter in determining the characteristics of the neurophysiological response to irrelevant speech and may also account for some of the heterogeneity in the behavioral literature of the ISE. It may thus be the case that the ISE is not a single phenomenon, expressed at a single locus in the brain. From a brain perspective, the irrelevant speech effect may instead be a complex phenomenon that is a composite of several underlying mechanisms, which depending on the working memory load, include top-down inhibition as well as recruitment of compensatory support and control processes. The dynamics of the adaptive interaction between these processes remains to be clarified in future research.

To conclude, in the interaction contrast (irrelevant speech $\times$ working memory), increases of activity were observed in the dorsolateral prefrontal cortex bilaterally, indicating increasing demands on executive working memory resources in conditions of auditory interference. These findings support the hypothesis of an adaptive recruitment of complementary working memory processes, characterizing ISE at a neuroimaging level in different processing contexts. In particular, the results from the present and the previous study taken in combination suggest that the neuronal correlates of irrelevant speech are dependent on the working memory load. At a low-load level, the performance level can be sustained through inhibition of task-irrelevant input (Gisselgård et al., 2003). At a high level of load, inhibitory modulation of irrelevant auditory input is not sufficient, and as a result, the brain adapts to the high-load context by engaging the dorsolateral prefrontal regions for adaptive support and control.

\section{Acknowledgments}

This work was supported by grants from the Swedish Medical Research Council (8246), the Karolinska Institute, the Swedish Bank Tercentenary Foundation, and the Knut and Alice Wallenberg Foundation.

\section{References}

Awh, E., Smith, E.E., Jonides, J., 1995. Human rehearsal processes and the frontal lobes: PET evidence. Annals of the New York Academy of Sciences 769, 97-117.

Awh, E., Jonides, J., Smith, E.E., Schumacher, E.H., Koeppe, R.A., Katz, S., 1996. Dissociation of storage and rehearsal in verbal working memory: evidence from positron emission tomography. Psychological Science 7, 25-31.

Baddeley, A., 1966a. The influence of acoustic and semantic similarity on long-term memory for word sequences. Quarterly Journal of Experimental Psychology 18, 302-309.

Baddeley, A., 1966b. Short-term memory for word sequences as a function of acoustic, semantic and formal similarity. Quarterly Journal of Experimental Psychology 18, 362-365.

Baddeley, A., 1992. Working memory. Science 255, 556-559

Baddeley, A., 1996. Exploring the central executive. Quarterly Journal of Experimental Psychology. A 1, 5-28.

Baddeley, A.D., 2000. The phonological loop and the irrelevant speech effect: some comments on Neath (2000) ([letter; comment]) . Psychonomic Bulletin \& Review 7, 544-549.

Baddeley, A., 2003. Working memory: looking back and looking forward. Nature Reviews. Neuroscience 4, 829-839.

Baddeley, A., Salame, P., 1986. The unattended speech effect: perception or memory? Journal of Experimental Psychology. Learning, Memory, and Cognition 12, 525-529. 
Braver, T.S., Cohen, J.D., Nystrom, L.E., Jonides, J., Smith, E.E., Noll, D.C., 1997. A parametric study of prefrontal cortex involvement in human working memory. NeuroImage 5, 49-62.

Bridges, A.M., Jones, D.M., 1996. Word dose in the disruption of serial recall by irrelevant speech: phonological confusions or changing state? Quarterly Journal of Experimental Psychology. A, Human Experimental Psychology 49A, 919-939.

Buchner, A., Irmen, L., Erdfelder, E., 1996. On the irrelevance of semantic information for the "irrelevant speech" effect. Quarterly Journal of Experimental Psychology. Human Experimental Psychology 49A, $765-779$.

Bunge, S.A., Ochsner, K.N., Desmond, J.E., Glover, G.H., Gabrieli, J.D.E., 2001. Prefrontal regions involved in keeping information in and out of mind. Brain 124, 2074-2086.

Burton, M.W., 2001. The role of inferior frontal cortex in phonological processing. Cognitive Science 25, 695-709.

Cabeza, R., Nyberg, L., 2000. Imaging cognition II: an empirical review of 275 PET and fMRI studies. Journal of Cognitive Neuroscience 12, 1-47.

Callicott, J.H., Mattay, V.S., Bertolino, A., Finn, K., Coppola, R., Frank, J.A., Goldberg, T.E., Weinberger, D.R., 1999. Physiological characteristics of capacity constraints in working memory as revealed by functional MRI. Cerebral Cortex 9, 20-26.

Casey, B.J., Trainor, R.J., Orendi, J.L., Schubert, A.B., Nystrom, L.E., Giedd, J.N., Castellanos, F.X., Haxby, J.V., Noll, D.C., Cohen, J.D., Forman, S.D., Dahl, R.E., Rapoport, A.J.L., 1997. A developmental functional MRI study of prefrontal activation during performance of a go-no-go task. Journal of Cognitive Neuroscience 9, 835-847.

Chawla, D., Rees, G., Friston, K.J., 1999. The physiological basis of attentional modulation in extrastriate visual areas. Nature Neuroscience 2, $671-676$.

Colle, H.A., 1980. Auditory encoding in visual short-term recall: effects of noise intensity and spatial locations. Journal of Verbal Learning and Verbal Behavior 19, 722-735.

Colle, H.A., Welsh, A., 1976. Acoustic masking in primary memory. Journal of Verbal Learning and Verbal Behavior 15, 17-32.

Dempster, F.N., 1991. Inhibitory processes: a neglected dimension of intelligence. Intelligence 15, 157-173.

D’Esposito, M., Postle, B.R., Ballard, D., Lease, J., 1999a. Maintenance versus manipulation of information held in working memory: an eventrelated fMRI study. Brain and Cognition 41, 66-86.

D’Esposito, M., Postle, B.R., Jonides, J., Smith, E.E., 1999b. The neural substrate and temporal dynamics of interference effects in working memory as revealed by event-related functional MRI. Proceedings of the National Academy of Sciences of the United States of America 96, $7514-7519$.

Fletcher, P.C., Henson, R.N., 2001. Frontal lobes and human memory: insights from functional neuroimaging. Brain 124, 849-881.

Fox, P.T., Mintun, M.A., 1989. Noninvasive functional brain mapping by change-distribution analysis of averaged PET images of $\mathrm{H} 215 \mathrm{O}$ tissue activity. Journal of Nuclear Medicine 30, 141-149.

Fox, P.T., Perlmutter, J.S., Raichle, M.E., 1985. A stereotactic method of anatomical localization for positron emission tomography. Journal of Computer Assisted Tomography 9, 141-153.

Friston, K.J., Holmes, A.P., Price, C.J., Buchel, C., Worsley, K.J., 1999. Multisubject fMRI studies and conjunction analyses. NeuroImage 10, 385-396.

Fuster, J.M., 1997. The Prefrontal Cortex: Anatomy, Physiology, and Neuropsychology of the Frontal Lobe. Lippincott-Raven, New York.

Genovese, C.L., Lazar, N.A., Nichols, T., 2002. Thresholding of statistical maps in functional neuroimaging using the false discovery rate. NeuroImage 15, 870-878.

Ghatan, P.H., Hsieh, J.C., Petersson, K.M., Stone-Elander, S., Ingvar, M., 1998. Coexistence of attention-based facilitation and inhibition in the human cortex. NeuroImage 7, 23-29.

Gisselgård, J., Petersson, K.M., Baddeley, A., Ingvar, M., 2003. The irrelevant speech effect: a PET study. Neuropsychologia 41, 1899-1911.

Goldman-Rakic, P.S., 1995. Architecture of the prefrontal cortex and the central executive. Annals of the New York Academy of Sciences 769, $71-83$.

Hanley, J.R., Bakopoulou, E., 2003. Irrelevant speech, articulatory suppression and phonological similarity: a test of the phonological loop model and the feature model. Psychonomic Bulletin \& Review 10, 435-444.

Hanley, J.R., Broadbent, C., 1987. The effects of unattended speech on serial recall following auditory presentation. British Journal of Psychology $78,287-297$.

Jones, D.M., Macken, W.J., 1993. Irrelevant tones produce an irrelevant speech effect: implications for phonological coding in working memory. Journal of Experimental Psychology. Learning, Memory, and Cognition $19,369-381$.

Jones, D., Morris, N., 1992. Irrelevant speech and serial recall: implications for theories of attention and working memory ([Review, 63 refs]) . Scandinavian Journal of Psychology 33, 212-229.

Jones, D.M., Miles, C., Page, J., 1990. Disruption of proofreading by irrelevant speech: effects of attention, arousal or memory? Applied Cognitive Psychology 4, 89-108.

Jones, D., Madden, C., Miles, C., 1992. Privileged access by irrelevant speech to short-term memory: the role of changing state. Quarterly Journal of Experimental Psychology. A, Human Experimental Psychology 44, 645-669.

Jonides, J., Smith, E.E., Koeppe, R.A., Awh, E., Minoshima, S., Mintun, M.A., 1993. Spatial working memory in humans as revealed by PET. Nature 363, 623-625.

Jonides, J., Schumacher, E.H., Smith, E.E., Lauber, E.J., Awh, E., Minoshima, S., Koeppe, A.R.A., 1997. Verbal working memory load affects regional brain activation as measured by PET. Journal of Cognitive Neuroscience 9, 462-475.

Jonides, J., Schumacher, E.H., Smith, E.E., Koeppe, R.A., Awh, E., Reuter-Lorenz, P.A., Marshuetz, C., Willis, C.R., 1998a. The role of parietal cortex in verbal working memory. Journal of Neuroscience 18, $5026-5034$.

Jonides, J., Smith, E.E., Marshuetz, C., Koeppe, R.A., Reuter-Lorenz, P.A., 1998b. Inhibition in verbal working memory revealed by brain activation. Proceedings of the National Academy of Sciences of the United States of America 95, 8410-8413.

Larsen, J.D., Baddeley, A., 2003. Disruption of verbal STM by irrelevant speech, articulatory suppression, and manual tapping: do they have a common source? Quarterly Journal of Experimental Psychology. A 56, $1249-1268$.

LeCompte, D.C., Shaibe, D.M., 1997. On the irrelevance of phonological similarity to the irrelevant speech effect. Quarterly Journal of Experimental Psychology. A, Human Experimental Psychology 50, 100-118.

LeCompte, D.C., Neely, C.B., Wilson, J.R., 1997. Irrelevant speech and irrelevant tones: the relative importance of speech to the irrelevant speech effect. Journal of Experimental Psychology. Learning, Memory, and Cognition 23, 472-483.

Miles, C., Jones, D.M., Madden, C.A., 1991. Locus of the irrelevant speech effect in short-term memory. Journal of Experimental Psychology. Learning, Memory, and Cognition 17, 578-584.

Miller, E.K., Cohen, J.D., 2001. An integrative theory of prefrontal cortex function. Annual Review of Neuroscience 24, 167-202.

Morris, N., Jones, D.M., 1990. Memory updating and working memory: the role of the central executive. British Journal of Psychology 81, 111-121.

Oldfield, R.C., 1971. The assessment and analysis of handedness: the Edinburgh inventory. Neuropsychologia 9, 97-113.

Paulesu, E., Frith, C.D., Frackowiak, R.S., 1993. The neural correlates of the verbal component of working memory. Nature 362, 342-345.

Petersson, K.M., Reis, A., Askelof, S., Castro-Caldas, A., Ingvar, M., 2000. Language processing modulated by literacy: a network analysis of verbal repetition in literate and illiterate subjects. Journal of Cognitive Neuroscience 12, 364-382.

Petrides, M., 1995. Functional organization of the human frontal cortex for mnemonic processing. Evidence from neuroimaging studies. Annals of the New York Academy of Sciences 769, 85-96.

Postle, B.R., Berger, J.S., D’Esposito, M., 1999. Functional neuroanatomical 
double dissociation of mnemonic and executive control processes contributing to working memory performance. Proceedings of the National Academy of Sciences of the United States of America 96, 12959-12964.

Price, C.J., Friston, K.J., 1997. Cognitive conjunction: a new approach to brain activation experiments. NeuroImage 5, 261-270.

Price, C., Indefrey, P., van Turennout, M., 1999. The neural architecture underlying the processing of written and spoken words. In: Brown, C.M., Hagoort, P. (Eds.), The Neurocognition of Language. Oxford Univ. Press, New York, pp. 211-233.

Salame, P., Baddeley, A., 1982. Disruption of short-term memory by irrelevant speech: implications for the structure of working memory. Journal of Verbal Learning and Verbal Behavior 21, 150-164.

Salame, P., Baddeley, A.D., 1986. Phonological factors in STM: similarity and the unattended speech effect. Bulletin of the Psychonomic Society 24, 263-265.

Salame, P., Baddeley, A., 1987. Noise, unattended speech and short-term memory. Ergonomics 30, 1185-1194.

Salame, P., Baddeley, A., 1989. Effects of background music on phonological short-term memory. Quarterly Journal of Experimental Psychology. A 44, 107-122.

Schumacher, E.H., Lauber, E., Awh, E., Jonides, J., Smith, E.E., Koeppe, R.A., 1996. PET evidence for an amodal verbal working memory system. NeuroImage 3, 79-88.
Shulman, G.L., Corbetta, M., Buckner, R.L., Raichle, M.E., Fiez, J.A., Miezin, F.M., Petersen, S.E., 1997. Top-down modulation of early sensory cortex. Cerebral Cortex 7, 193-206.

Smith, E.E., Jonides, J., 1997. Working memory: a view from neuroimaging. Cognitive Psychology 33, 5-42.

Smith, E.E., Jonides, J., 1999. Storage and executive processes in the frontal lobes. Science 283, 1657-1661.

Smith, E.E., Jonides, J., Koeppe, R.A., 1996. Dissociating verbal and spatial working memory using PET. Cerebral Cortex 6, 11-20.

Sylvester, C.Y., Wager, T.D., Lacey, S.C., Hernandez, L., Nichols, T.E., Smith, E.E., Jonides, J., 2003. Switching attention and resolving interference: fMRI measures of executive functions. Neuropsychologia 41, $357-370$.

Talairach, J., Tournoux, P., 1988. Co-Planar Stereotaxic Atlas of the Human Brain. Thieme Medical Publishers Inc., New York.

Wienhard, K., Dahlbom, M., Eriksson, L., Michel, C., Bruckbauer, T., Pietrzyk, U., Heiss, W.D., 1994. The ECAT EXACT HR: Performance of a new high resolution positron scanner. Journal of Computer Assisted Tomography $18,110-118$.

Worsley, K., Marrett, S., Neelin, P., Vandal, A.C., Friston, K.J., Evans, A., 1996. A unified statistical approach for determining significant signals in images of cerebral activation. Human Brain Mapping 4, $58-73$ 